\title{
Knowledge and Perceptions of Final Year Medical Students in Iraqi Universities about Generic Medicines
}

\author{
Adheed Khalid Sharrad ${ }^{1 *}$ and Mohamed Azmi Hassali ${ }^{2}$ \\ ${ }^{1}$ Discipline of Social and Administrative Pharmacy, School of Pharmaceutical Sciences, Universiti Sains Malaysia \\ ${ }^{2}$ Discipline of Social and Administrative Pharmacy, School of Pharmaceutical Sciences, Universiti Sains Malaysia
}

\begin{abstract}
Objective: To explore and evaluate final year medical students' perceptions of and knowledge about generic medicines in Iraqi universities.

Methods: A cross-sectional survey was conducted between $1^{\text {st }}$ June 2010 and $31^{\text {st }}$ July 2010 in six Iraqi public universities offering courses in medicine.

Results: Responses were received from 546 medical students (response rate $69.6 \%$ ).More than $60 \%$ of study participants thought that generic medicines are inferior, less effective and produce more side effects compared to brand name medicines. These findings highlight that final year medical students need a better understanding of the principles and concepts of bioavailability and bioequivalence if they are to contribute appropriately t o generic medicine use.
\end{abstract}

Conclusions: This study clearly shows that medical students in Iraq lack of understanding on issues related to generic medicine use. In order to encourage the use of generic medicines in Iraq, medical students need to be receiving a better education on the issues relating to generic medicines and generic prescribing. This could be achieved by including the relevant topics in the current medical education curriculum.

Keywords: Generic medicines; Generic prescribing; Bioequivalence; Perceptions

\section{Introduction}

The reasons especially among authorities in Europe for the increasing focus on medicines is their expenditure growth in recent years, greater that other components, leading to pharmaceutical expenditure now the largest or equal largest component. In addition, the need to continue to provide equitable and comprehensive healthcare in the face of pressures including demographics, rising patient expectations and the continued launch of new premium priced drugs with pressures from consultants, patients and others to prescribe these [1-3].

An increasing strategy employed by authorities surrounds increasing the utilisation of generics as well as introducing strategies to obtain low prices to take full advantage of over $\$ 100 \mathrm{bn} /$ year of products likely to lose their patent by 2012 - especially with such wide variation in current prices of generics [3-6].

The debate surrounding generic prescriptions has centred on issues relating to bioequivalence, quality and safety. [2,7-13] .Some of these issues relate to the fact that in some European countries there are branded generics. This can cause patient confusion leading potentially to medication errors. In Iraq, Concern has been expressed by physicians practicing elsewhere about the efficacy of generic Medication. This debate has centered on issues related to bioequivalence and potential confusion that might arise when changes of medicine brands occur in some patient populations [14]. Furthermore, previous studies have shown that changing existing prescribing behaviors is difficult. $[15,16]$. So, it is important to train medical students with getting used to INN prescribing as happens in the UK for instance and reinforced in the community [1,17]; influencing existing prescribers can appreciably enhance prescribing efficiency. Consequently, would suggest a dual strategy. However, may be easier to start with students as the first group. The aims of this study are to explore and evaluate final-year medical students' perception and knowledge of generic medicines and generic prescribing in Iraqi universities.

\section{Methodology}

\section{Development of the survey questionnaire}

As Hassali and associates used the questionnaire in their study and is validated also, it is reasonable to use pre-validated questionnaire in survey research. Therefore, on this pretext we decided to use the validated questionnaire which we revalidated before the execution in the current study [18].

A total of 23 survey items, classified into four groups, were developed. The first part consisted of three demographic questions: age, gender, and the university at which the participants were currently enrolled. In the second part, items were pooled under the heading of 'knowledge of bioequivalence of generic medicines'. This section included a question which asked the student to select the correct bioequivalence regulatory limits when comparing generic medicines with innovator brands according to the requirements of the US Food and Drug admiistration (FDA). The other four questions were framed in a five-point Likert scale format ( 5 = 'strongly agree'; 4 = 'agree'; $3=$ 'neutral'; $2=$ 'disagree' and $1=$ 'strongly disagree'). This type of scale was chosen because its construction is relatively simple and the interpretation of results is straightforward [19]. The third part of the survey contained eight items which evaluated the medical students' understanding of brand name medicines versus generic medicines.

*Corresponding author: Mr. Adheed Khalid Sharrad, BSc Pharm, MSc, Discipline of Social and Administrative Pharmacy, School of Pharmaceutical Sciences, Universiti Sains Malaysia, 11800 Penang, Malaysia, E-mail: adheed_k@yahoo. co.uk

Received May 26, 2011; Accepted June 28, 2011; Published June 30, 2011

Citation: Sharrad AK, Hassali MA (2011) Knowledge and Perceptions of Final Year Medical Students in Iraqi Universities about Generic Medicines. J Bioequiv Availab 3: 086-091. doi:10.4172/jbb.1000065

Copyright: (c) 2011 Sharrad AK, et al. This is an open-access article distributed under the terms of the Creative Commons Attribution License, which permits unrestricted use, distribution, and reproduction in any medium, provided the original author and source are credited. 
Citation: Sharrad AK, Hassali MA (2011) Knowledge and Perceptions of Final Year Medical Students in Iraqi Universities about Generic Medicines. J Bioequiv Availab 3: 086-091. doi:10.4172/jbb.1000065

These items were also framed in a five-point Likert rating scale. The fourth part of the questionnaire consisted of seven items designed to evaluate the medical students' perceptions of education they were currently receiving. Similarly to part three, these questions were also answered using a five-point Likert scale.

In order not to overlook any of the students' opinions on the issue of generic and brand name medicines, a blank space was provided on the last page of the survey for the respondents to write down their views.

\section{Face and content validation of the paper survey}

Three lecturers of pharmacology from Basra college of Medicine and Pharmacy with experience in the field of medicines were asked to evaluate the relevance, clarity and conciseness of the items included in the questionnaire. The observations and comments given by the lecturers were taken into account [20]. In order to test the validity and the reliability $[21,22]$ of the survey form, the revised questionnaire was pilot-tested by administering it to a convenient sample of 20 medical students who were not participating in the main study. The overall Cronbach's alpha value was 0.72 .

\section{Study design and sample size}

A cross-sectional survey was conducted between $1^{\text {st }}$ June 2010 and $31^{\text {st }}$ July 2010. Convenience sample method was used, six universities were choosing from the middle and south of Iraq. The sampling frame was all final-year medical students in six universities who were enrolled during the period of the study. The number of enrolled students during the study period was obtained from the Dean's Office in each university as shown in Table 1.

\section{Survey administration and timeframe}

This descriptive and analysis study was conducted over a period of two months, between the $1^{\text {st }}$ Jun 2010 and the $31^{\text {st }}$ of July 2010. In order to inform the students about the objectives of the survey, an explanatory letter attached to the survey questionnaire was distributed to all of the participants. The students received the survey questionnaire from the respective lecturers in each university. Permission to approach the students and to conduct the study was obtained from the Ministry of Higher Education and Scientific Research in Iraq.

\begin{tabular}{|l|l|}
\hline University & Number of enrolled final year students \\
\hline $\mathbf{1}$ & 286 \\
\hline $\mathbf{2}$ & 110 \\
\hline $\mathbf{3}$ & 56 \\
\hline $\mathbf{4}$ & 258 \\
\hline $\mathbf{5}$ & 20 \\
\hline $\mathbf{6}$ & 75 \\
\hline Total & 785 \\
\hline
\end{tabular}

Table 1: Final-year medical student enrolment at six Iraq universities, 2010.

\begin{tabular}{|l|l|l|l|}
\hline University & $\begin{array}{l}\text { Number of enrolled } \\
\text { final year students }\end{array}$ & $\begin{array}{l}\text { Number of students } \\
\text { who responded }\end{array}$ & $\begin{array}{l}\text { Percentage of students } \\
\text { who responded (\%) }\end{array}$ \\
\hline 1 & 286 & 196 & 68.5 \\
\hline 2 & $90^{*}$ & 65 & 72.2 \\
\hline 3 & 56 & 36 & 64.2 \\
\hline 4 & 258 & 188 & 72.8 \\
\hline 5 & 20 & 16 & 80 \\
\hline 6 & 75 & 45 & 60 \\
\hline Total & 785 & 546 & 69.6 \\
\hline \multicolumn{2}{|r|}{ " 20 students were excluded for pilot study } \\
\hline
\end{tabular}

\begin{tabular}{|l|l|l|l|}
\hline University & Number of respondents & Mean age (SD) & $\begin{array}{l}\text { Gender } \mathbf{( M = M a l e ) ~ ( F = ~} \\
\text { Female) }\end{array}$ \\
\hline 1 & 196 & $23.87(0.78)$ & $\mathrm{M}=103 ; \mathrm{F}=93$ \\
\hline 2 & 65 & $23.71(0.63)$ & $\mathrm{M}=28 ; \mathrm{F}=37$ \\
\hline 3 & 36 & $23.77(0.68)$ & $\mathrm{M}=12 ; \mathrm{F}=36$ \\
\hline 4 & 188 & $23.74(0.71)$ & $\mathrm{M}=87 ; \mathrm{F}=101$ \\
\hline 5 & 16 & $23.87(0.71)$ & $\mathrm{M}=6 ; \mathrm{F}=10$ \\
\hline 6 & 45 & $23.66(0.71)$ & $\mathrm{M}=27 ; \mathrm{F}=18$ \\
\hline Total & 546 & $23.78(0.72)$ & $\begin{array}{l}\mathbf{M}=\mathbf{2 6 3} \\
\mathbf{F}=\mathbf{2 8 3}\end{array}$ \\
\hline
\end{tabular}

Table 3: Demographic characteristics according to university.

\begin{tabular}{|l|l|l|}
\hline Response & Frequency & Percent (\%) \\
\hline $\mathbf{8 0} \%-\mathbf{1 2 0} \%$ & 54 & 9.9 \\
\hline $\mathbf{8 0} \mathbf{- 1 2 5 \%}$ & 49 & 9.0 \\
\hline $\mathbf{9 0} \%-\mathbf{1 0 0} \%$ & 76 & 13.9 \\
\hline $\mathbf{9 5 \% - 1 0 0 \%}$ & 99 & 18.1 \\
\hline $\mathbf{9 5 \% - 1 0 5 \%}$ & 64 & 11.7 \\
\hline i don't know & 204 & 37.4 \\
\hline Total & 546 & $\mathbf{1 0 0 . 0}$ \\
\hline
\end{tabular}

Table 4: Responses to question 4

\section{Data collection}

Responses from the students were collected by the medical lecturers in each university and were entered (key - in) into the Statistical Package for Social Sciences (SPSS) for Windows, version 16, by the researcher in order to perform statistical analysis.

\section{Data analysis}

Data analysis was performed using SPSS ${ }^{\circ}$ for Windows, version 16 [23] The mean ( \pm SD) was calculated for the continuous variables, and frequencies were measured for the categorical variables. Associations between groups were examined using chi-square or Fisher exact tests whenever necessary. For categorical variables, Fisher's exact test is preferred over the chi-square test if $20-25 \%$ or more cells in the table have expected frequencies of less than five, or if any of the expected frequencies are less than one $[22,24,25]$. Data which emerged from the domains using the Likert scale as a measurement were analysed statistically as non-parametric data [26-28]. However, the response categories in the Likert scale have a ranking order, but the intervals between the values cannot be presumed to be equal $[29,30]$.

For this survey data, a default Monte Carlo simulation in the SPSS software was used to estimate Fisher's exact p-values as the data set was large and normal exact computations require a significant amount of time and memory from the computer. A two-sided $99 \%$ confidence level Monte Carlo estimate of Fisher's exact p-value was computed, with a p-value of 0.05 or less taken to demonstrate statistical significance.

\section{Results}

The total number of medical students in the six universities in question in Iraq during the time of the survey was 785. By the end of the survey period, 546 students had responded to the survey (response rate $=69.6 \%$ ). The responses of each university are shown in Table 2.

The average age of the respondents was $23.78 \pm 0.72$ years. Of the respondents, $248(45.4 \%)$ were 24 years old, and $283(51.8 \%)$ of the respondents were female (Table 3 ).

The first item on the questionnaire asked the students to select the correct bioequivalence limits allowed by the FDA when comparing an innovator drug with a generic one. The following explanation was provided with the question: 
Citation: Sharrad AK, Hassali MA (2011) Knowledge and Perceptions of Final Year Medical Students in Iraqi Universities about Generic Medicines. J Bioequiv Availab 3: 086-091. doi:10.4172/jbb.1000065

\begin{tabular}{|c|c|c|c|c|c|c|c|}
\hline \multirow{2}{*}{ Survey question/statement } & \multicolumn{5}{|l|}{ Response } & \multicolumn{2}{|l|}{ P Value } \\
\hline & SD (\%) & $\mathrm{D}(\%)$ & $\mathrm{N}(\%)$ & $A(\%)$ & SA $(\%)$ & Gender & University \\
\hline $\begin{array}{l}\text { All generic products of a particular medicine that are rated as "generic } \\
\text { equivalents" are therapeutically equivalent to the innovator brand product. }\end{array}$ & $103(18.9)$ & $298(54.6)$ & $33(6)$ & $75(13.7)$ & $37(6.8)$ & $0.355^{¥}$ & $<0.001^{*}$ \\
\hline $\begin{array}{l}\text { All generic products of a particular medicine that are rated as "generic } \\
\text { equivalents" are therapeutically equivalent to each other }\end{array}$ & $153(28.1)$ & $252(46.2)$ & $77(14.1)$ & $49(9.0)$ & $15(2.7)$ & $0.920^{*}$ & $<0.001^{*}$ \\
\hline $\begin{array}{l}\text { I have not been introduced to the issues of bioequivalence for generic drugs } \\
\text { during my pharmacy education. }\end{array}$ & $14(2.6)$ & $33(6.0)$ & $109(20.0)$ & $234(42.9)$ & $156(28.6)$ & $0.901^{*}$ & $0.502^{*}$ \\
\hline $\begin{array}{l}\text { I need more information on how bioequivalence tests are conducted for } \\
\text { generic medicines. }\end{array}$ & $16(2.9)$ & $34(6.2)$ & $83(15.2)$ & $262(48.0)$ & $151(27.7)$ & $0.319^{¥}$ & $0.883^{*}$ \\
\hline
\end{tabular}

Note: $\mathrm{SD}=$ Strongly Disagree, $\mathrm{D}=$ Disagree, $\mathrm{N}=$ Neutral, $\mathrm{A}=$ Agree, $\mathrm{SA}=$ strongly agree

*Fisher exact test

${ }^{*}$ chi-square

Table 5: The responses to other questions on knowledge of bioequivalence are shown in Table.

\begin{tabular}{|c|c|c|c|c|c|c|c|}
\hline \multirow[t]{2}{*}{ Survey question/statement } & \multicolumn{5}{|l|}{ Response } & \multicolumn{2}{|l|}{ P Value } \\
\hline & SD (\%) & $\mathrm{D}(\%)$ & $\mathrm{N}(\%)$ & $A(\%)$ & SA (\%) & Gender & University \\
\hline Generic medicine is bioequivalent to its brand medicine & $36(6.6)$ & $305(55.9)$ & $79(14.5)$ & $79(14.5)$ & $47(8.6)$ & $0.822^{¥}$ & $0.013^{*}$ \\
\hline Generic medicine must contain the same dose as the brand medicine & 98(17.9) & 223(40.8) & $110(20.1)$ & $85(15.6)$ & $30(5.5)$ & $0.347^{*}$ & $0.935^{*}$ \\
\hline $\begin{array}{l}\text { Generic medicines must be in the same dosage forms (e.g. tablet, capsules) } \\
\text { as the brand name medicines. }\end{array}$ & $174(31.9)$ & 192(35.2) & $90(16.5)$ & $75(13.7)$ & $15(2.7)$ & $0.006^{*}$ & $0.494^{*}$ \\
\hline Generic medicines are of lower quality compared to brand name medicine. & $57(10.4)$ & $34(6.2)$ & $78(14.3)$ & 207(37.9) & $170(31.1)$ & $0.059^{*}$ & $<0.001^{*}$ \\
\hline $\begin{array}{l}\text { Generic medicines are less effective as compared to the brand name } \\
\text { medicines }\end{array}$ & $14(2.6)$ & $47(8.6)$ & $121(22.2)$ & $201(36.8)$ & $163(29.9)$ & $0.396^{*}$ & $0.570^{*}$ \\
\hline $\begin{array}{l}\text { Generic medicines produce more side effects compared to the brand name } \\
\text { medicines. }\end{array}$ & $40(7.3)$ & $84(15.4)$ & $86(15.8)$ & $201(36.8)$ & $135(24.7)$ & $0.155^{*}$ & $0.047^{*}$ \\
\hline Generic medicines are less expensive than brand medicines & $19(3.5)$ & $17(3.1)$ & $49(9)$ & $283(51.8)$ & $178(32.6)$ & $0.224^{*}$ & $<0.001^{*}$ \\
\hline $\begin{array}{l}\text { Brand name medicines are required to meet higher safety standards than } \\
\text { generic medicines. }\end{array}$ & $41(7.5)$ & $44(8.1)$ & $85(15.6)$ & $200(36.6)$ & $176(32.2)$ & $0.292^{¥}$ & $0.397^{*}$ \\
\hline
\end{tabular}

Note: $\mathrm{SD}=$ Strongly Disagree, $\mathrm{D}=$ Disagree, $\mathrm{N}=$ Neutral, $\mathrm{A}=$ Agree, $\mathrm{SA}=$ strongly agree

${ }^{*}$ Fisher exact test

*chi-square

Table 6: The responses to other questions about understanding of brand name versus generic name are shown in Table.

\begin{tabular}{|c|c|c|c|c|c|c|c|}
\hline \multirow[t]{2}{*}{ Survey question/statement } & \multicolumn{5}{|l|}{ Response } & \multicolumn{2}{|l|}{ P Value } \\
\hline & SD (\%) & $\mathrm{D}(\%)$ & $\mathrm{N}(\%)$ & $A(\%)$ & SA (\%) & Gender & University \\
\hline $\begin{array}{l}\text { I need more information on the issues pertaining to the safety and efficacy } \\
\text { of generic medicine. }\end{array}$ & $62(11.4)$ & $32(5.9)$ & $43(7.9)$ & 182(33.3) & $227(41.6)$ & $0.477 ¥$ & $0.013^{*}$ \\
\hline $\begin{array}{l}\text { From the knowledge that I have, I'm confident in prescription written by } \\
\text { generic medicine rather than brand medicine }\end{array}$ & $5(0.9)$ & $95(17.4)$ & $93(17)$ & $181(33.2)$ & $172(31.5)$ & $0.503^{*}$ & $<0.001^{*}$ \\
\hline $\begin{array}{l}\text { I find it easier to recall a medicine's therapeutic class using generic names } \\
\text { rather than brand name }\end{array}$ & $10(1.8)$ & $51(9.3)$ & $140(25.6)$ & 256(46.9) & $89(16.3)$ & $0.031^{*}$ & $0.015^{*}$ \\
\hline $\begin{array}{l}\text { I believe pharmacists are one of the important health care professionals to } \\
\text { advise me on generic medicine }\end{array}$ & $36(6.6)$ & $25(4.6)$ & $112(20.5)$ & 203(37.2) & $170(31.10$ & $0.596^{*}$ & $<0.001^{*}$ \\
\hline $\begin{array}{l}\text { I believe my future prescribing habits will be influenced by my senior } \\
\text { colleagues and medical consultants }\end{array}$ & $14(2.6)$ & $63(11.5)$ & $96(17.6)$ & $219(40.1)$ & $154(28.2)$ & $0.020^{\mp}$ & $0.233^{*}$ \\
\hline $\begin{array}{l}\text { I believe advertisements by the drug companies will influence my future } \\
\text { prescribing patterns }\end{array}$ & $14(2.6)$ & $96(17.6)$ & $126(23.1)$ & $219(40.1)$ & $91(16.7)$ & $0.471^{*}$ & $<0.001^{*}$ \\
\hline $\begin{array}{l}\text { I believe that the topic of cost-effective prescribing is well covered in my } \\
\text { medical education }\end{array}$ & $139(25.5)$ & 186(34.1) & $70(12.8)$ & $105(19.2)$ & $46(8.4)$ & $0.103^{*}$ & $<0.001^{*}$ \\
\hline
\end{tabular}

Note: $S D=$ Strongly Disagree, $D=$ Disagree, $N=$ Neutral, $A=$ Agree, $S A=$ strongly agree

${ }^{*}$ Fisher exact test

${ }^{*}$ chi-square

Table 7: The responses to other questions regarding perception of current prescribing education are shown in Table.

In pharmacology, the term 'bioavailability' refers to the rate (how fast) and the extent (how much) to which an active ingredient is absorbed and becomes available at the site of the drug action. The FDA organisation considers a generic product to be bioequivalent if its bioavailability is within an a specified range compared with the currently marketed branded product.

After this statement, the following question was asked:

The regulatory limits applied are that the $90 \%$ confidence intervals for the ratios (generic product: brand name product) of the areas under the plasma drug concentration versus time curves and the maximum plasma drug concentrations must fall between...

Six answer options were given, the correct answer being 80-125\%.

The responses are shown in Table 4. Only 49 (9.0\%) of the students answered the question correctly, while 293 (53.6\%) answered incorrectly and $204(37.0 \%)$ did not attempt to provide a numerical answer.

The responses to other questions relating to the students' knowledge of bioequivalence are shown in Table 5 . 
More than $70 \%$ of the respondents did not believe that generic medicines are therapeutically equivalent to the corresponding brand name medicines, or even to each other. There was a statistically significant difference between the responses to these two questions according to universities ( $\mathrm{p}<0.001$ for both questions). More than $70 \%$ of the respondents did not possess sufficient information about bioequivalence for generic medicine and how bioequivalence tests are conducted for generic medicines. There were no statistically significant differences according to gender and the different universities for these two questions.

The responses to questions about understanding of brand name versus generic name are shown in Table 6. More than $60 \%$ of the respondents thought that a generic medicine was not bioequivalent to the corresponding branded medicine. There was a statistically significant difference in the responses to this question from different universities. More than half of the respondents did not know that the generic medicine must be presented in the same dose and dosage form as the brand name medicine. There was a statistically significant gender difference in the responses to the question regarding the form of the dosage $(\mathrm{p}=0.006)$. With regard to quality and efficacy, around two-thirds of the respondents agreed that generic medicines are of a lower quality (69.7\%), are less effective $(66.7 \%)$, produce more side effects (61.5\%) and adhere to lower safety standards (68.8\%) than branded medicines. There was a statistically significant difference in the responses to the question about quality between the different universities $(\mathrm{p}<0.001)$. According to the question regarding the price of generic medicines, $84.4 \%$ of the respondents believed that generic medicines are less expensive than brand name medicines. A statistically significant difference $(\mathrm{p}<0.001)$ was found between the responses of the different universities.

With regards to the participants' perceptions of the current education in prescriptions, Table 7 shows the responses to these questions. Around $80 \%$ of the respondents needed more information on issues pertaining to the safety and efficacy of generic medicines. Statistically significant differences $(p=0.013)$ were noted in the responses to this question from the various universities. Of the respondents, 353(64.7\%) felt confident enough to prescribe medicines according to their generic name rather than a brand name. Statistically significant differences $(\mathrm{p}<0.001)$ were noted in the responses to this question from the different universities. Of the respondents, $63.2 \%$ found it easier to recall a medicine's therapeutic class using generic names rather than brand names. Statistically significant differences ( $p$ $=0.015$ ) was found in the responses to this question from the different universities and between genders $(p=0.050)$. Of the respondents, $68.3 \%$ believed that pharmacists would give them advice in the future with regard to generic medicines. Statistically significant differences were found between the responses to this question from the different universities $(p<0.001)$. Almost $68.3 \%$ of the respondents agreed that their future prescribing habits would probably be influenced by their senior colleagues and medical consultants. Statistically significant gender differences were found in the responses to this question $(\mathrm{p}=0.020)$, as a higher proportion of female students strongly agreed or agreed with this item. More than half of the respondents $(56.8 \%)$ believed that advertisements by drug companies would influence their future prescribing patterns. Statistically significant differences were found in the response to this question from the various universities $(p<0.001)$. Around $60 \%$ of the respondents believed that their university did not adequately cover the topic of cost-effective prescribing on their medical curriculum.

\section{Discussion}

\section{Part 1 -Demographics and response rate}

To the best of our knowledge, this is the first study in Iraq which has evaluated the knowledge and perceptions of final-year medical students in universities in Iraq towards generic medicine. In the present study, an overall response rate of $69.6 \%$ was recorded. One reason for a lack of responses to this survey may be the lack of information regarding generic medicines among the students. With regard to the respondents demographic characteristics, $51.8 \%$ of the respondents were female, while $48.2 \%$ were male. The average age of the students was $23.78 \pm$ 0.72 years old.

\section{Part 2 - Understanding of the bioequivalence of generic medicines}

According to the FDA, the determination of the bioequivalence of a generic medicine involves an assessment of pharmacokinetic parameters such as the area under the curve (AUC) and peak concentration $\left(\mathrm{C}_{\max }\right)$, as well as the calculation of a $90 \%$ confidence interval for the ratio of the averages of these parameters for the two products that are compared, usually a test product (generic product) against a reference product (the innovator or the branded product). The calculated confidence interval should fall within a conventionally established bioequivalence range of $80 \%$ to $125 \%$ for the ratio of the product averages. This reflects that the difficulty of the topics of pharmacokinetics and bio-pharmaceutics make it difficult for students to understand them. In the first question, which asked the students about their knowledge of the bioequivalence limits for the approval of generic medicine by the FDA, only $9.0 \%$ ( $\mathrm{n}$ $=49)$ of the students gave the right answer and $37.4 \%(n=204)$ of the respondents had no idea. This reflects the deficiency in the students' knowledge of pharmacokinetic parameters, which are important in the areas of bioequivalence and bioequivalence testing with generic medicine. The poor response to this question in this study confirmed the response to the same question in the study which was conducted in Australia by Hassali and his group [18].These two studies in Australia and Iraq clarify that topics relating to bioequivalence are not covered and that these topics are important for medical students during their education, as their education will help them to be more confident in prescribing generic medicine in the future.

\section{Part 3 - Understanding of brand name versus generic medicines}

More than $70 \%$ of the respondents did not believe that generic medicines were therapeutically equivalent to the corresponding brand name medicines, or even to each other. This is due to bad experiences among patients with regard to the generic medicines used in Iraq over the last 20 years. During this time, most medicines which have been imported into the country have not undergone a quality control check, due to the shortage of medicine as a result of an international embargo which has been in place since $1990^{\prime}(31)$. This result was in line with the results of other studies conducted in different countries [2,7-13]. While The findings of the current study are not in line with those of the previous study which was carried out in Australia by Hassali et al. [18], and in which more than $80 \%$ of the respondents believed that a generic medicine was bioequivalent to the corresponding brand name medicine. Statically analysis show significant differences among universities, the differences in the responses might occur due to deficiency in the universities curricula in teaching this topic to their students. According to questions which explored the medical students' knowledge of dosage forms and doses when comparing generic medicines with branded 
medicines according to the FDA's requirements, more than half of the respondents did not know the definition of generic medicine according to this organisation. Under the FDA's regulations, a generic medicine must contain identical amounts of the same active ingredients in the same dosage form as a branded medicine [32]. Around half of the respondents were not aware of these two facts. This response pattern might be influenced by lack of education about generic medicines. Statistically analysis show significant differences according to gender with the fact that the generic medicine must be in same dosage forms, a higher proportion of male students either strongly disagreed or disagreed with this question compared to their female counterparts. This response reflects a lack of information regarding the requirements of generic medicines according to the FDA. The findings of the current study are in line with those of a previous study carried out in Australia by Hassali [18].

According to the questions that evaluated the medical students' knowledge of the quality and effect of generic medicines when compared to brand name medicines, 377 of the respondents (69\%) believed that the generic medicines in Iraq were of a lower quality. Of the respondents, $336(61.5 \%)$ thought that generic medicines would cause more side effects than brand name medicines. Statically analysis showed significant differences among universities and the differences in the responses might occur due to differences in the universities curricula in teaching this topic to their students. While 433 of the respondents $(66.7 \%)$ believed that they were less effective than their brand name counterparts. These results were in line with the results of the study conducted in Australia by Hassali [18]. Which illustrated the deficit in medical students' knowledge of generic medicines. More than $80 \%$ of the respondents were fully aware that generic medicines are less expensive than brand name medicines. Statically analysis showed significant differences among universities, the differences in the responses might occur due to differences in the universities curricula in teaching this topic to their students. Of the respondents, $376(68.8 \%)$ thought that brand name medicines were required to meet higher standards than generic medicines.

\section{Part 4 - Perceptions of the current education in prescribing}

Most of the respondents in the current study (74.9\%) said that they would have liked more information on the safety and efficacy of generic medicines during their years of medical education, The highest proportion of respondents from the University No. 6, while the lowest came from the University of respondents No. 5. Of the respondents, 353 (64.7\%) were more confident in prescribing using generic names rather than brand names because the curriculum deals with generic names more than brand names, the highest proportion of respondents from the university No.3, while the lowest came from the university No.5. This may be reflective of different styles of teaching among universities .Of the respondents, 345(63.2\%) found it easier to recall a medicine's therapeutic class using generic names rather than brand name, The highest proportion of respondents from the university No.6, while the lowest came from the university No.2. The proportion of males is higher than the proportion of females in relation to this question. Nearly two-third of the respondents thought that pharmacists were one of the most important groups of healthcare professionals in terms of providing medical students with advice on generic medicines, while in a similar study in Australia [18]. The respondents were more confident in pharmacists, with $86.8 \%$ thinking that pharmacists comprised one of the most important teams of healthcare professionals in terms of providing the respondents with advice. This reflects the different views held with regard to pharmacists in both countries; in
Iraq, many private pharmacies are run by non-medical staff, and this decreases patients' confidence in pharmacists' advice. More than half of the students in Iraq agreed that advertising by drug companies would influence their future prescribing patterns, while in Australia, one quarter of the students believed that advertising from companies would influence their prescribing patterns [18]. These results was in line with the study conducted by Godman et al. [33] where more than half the physicians stated that Pharma Company activity would influence future prescribing habits as Pharma Companies spend a great deal of money on marketing activities as well as physician education [33]. More than half of the students in Iraq and Australia believed that their universities did not adequately cover the topic of cost-effective prescribing in their medical curriculum. A statistically significant difference was noted for all these six responses among universities; The differences in the responses might occur due to differences in the universities curricula in teaching these topics to their students. In the present study, almost two-thirds of the medical students strongly agreed or agreed that their future prescribing habits would probably be influenced by their senior colleagues and medical consultants. Statistically analysis showed significant differences according to gender, where high response from Female students than male students was noted. In psychology it is generally seen that female have a tendency to follow their seniors and in that context, in the current study, females are influenced by their senior colleagues opinions and decisions. This result is in line with the results of the study conducted in Australia by Hassali et al. [18], in which $92 \%$ of the respondents strongly agreed or agreed that their future prescribing habits would probably be influenced by their senior colleagues and medical consultants. Similarly, in a previous study conducted among interns in Australia, $80 \%$ of the medical interns believed that their consultants would influence their prescribing practices [34]. This clarifies the deficiency in topics that encompass prescription-related issues in our universities, as their actual prescribing training will only start in the hospital.

\section{Limitations of the study}

The number of students who participated in this study was relatively small compared to the total number of students who are enrolled in medical colleges in Iraq. Therefore, these results may not necessarily be generalisable to all medical students.

\section{Conclusion}

This study clearly shows that medical students in Iraq lack an extensive understanding of the concept of bioequivalence and the safety and quality of generic medicines. In order to encourage the use of generic medicines in Iraq, medical students need to be receiving a better education on the issues relating to generic medicines and generic prescribing. This could be achieved by including the relevant topics in the current medical education curriculum.

\section{Reference}

1. Duerden MG, Hughes DA (2010) Generic and therapeutic substitutions in the UK: are they a good thing? Br J Clin Pharmacol 70: 335-341.

2. Sermet C, Andrieu V, Godman B, Van Ganse E, Haycox A, Reynier JP (2010) Ongoing pharmaceutical reforms in France: implications for key stakeholder groups. Appl Health Econ Health Policy 8: 7-24.

3. Godman B, Shrank W, Andersen M, Berg C, Bishop I, et al. (2010) Comparing policies to enhance prescribing efficiency in Europe through increasing generic utilization: changes seen and global implications. Expert Rev Pharmacoecon Outcomes Res 10: 707-722.

4. Jack A (2008) Balancing big pharma's books. BMJ 336: 418-419. 
Citation: Sharrad AK, Hassali MA (2011) Knowledge and Perceptions of Final Year Medical Students in Iraqi Universities about Generic Medicines. J Bioequiv Availab 3: 086-091. doi:10.4172/jbb.1000065

5. Simoens S (2008) Trends in generic prescribing and dispensing in Europe. Expert Review of Clinical Pharmacology 1: 497-503.

6. Simoens S (2007) International comparison of generic medicine prices. Curr Med Res Opin 23: 2647-2654

7. Håkonsen H, Eilertsen M, Borge H, Toverud EL (2009) Generic substitution: additional challenge for adherence in hypertensive patients? Curr Med Res Opin 25: 2515-2521.

8. Figueiras MJ, Marcelino D, Cortes MA (2008) People's views on the level of agreement of generic medicines for different illnesses. Pharm World Sci 30: 590-594.

9. Figueiras MJ, Alves NC, Marcelino D, Cortes MA, Weinman J, et al. (2009) Assessing lay beliefs about generic medicines: Development of the generic medicines scale. Psychol Health Med 14: 311-321.

10. Frisk P, Rydberg T, Carlsten A, Ekedahl A (2011) Patients' experiences with generic substitution: a Swedish pharmacy survey. Journal of Pharmaceutical Health Services Research.

11. Chua GN, Hassali MA, Shafie AA, Awaisu A (2010) A survey exploring knowledge and perceptions of general practitioners towards the use of generic medicines in the northern state of Malaysia. Health policy 95: 229-235

12. Birkett DJ (2003) Generics-equal or not? Australian Prescriber 26 :85-86.

13. McGavock H (2001) Generic substitution-issues relating to the Australian experience. Pharmacoepidemiol Drug Saf 10: 555-556.

14. Sharrad AK, Hassali MA, Shafie AA (2009) Generic medicines: Perceptions of Physicians in Basrah, Iraq. Australasian Medical Journal 1.

15. Armstrong D, Reyburn H, Jones R (1996) A study of general practitioners' reasons for changing their prescribing behaviour. BMJ 312: 949-952.

16. Helin-Salmivaara A, Huupponen R, Klaukka T, Hoppu K (2003) Focusing on changing clinical practice to enhance rational prescribing--collaboration and networking enable comprehensive approaches* 1 . Health policy 66: 1-10.

17. McGinn D, Godman B, Lonsdale J, Way R, Wettermark B, et al. (2010) Initiatives to enhance the quality and efficiency of statin and PPI prescribing in the UK: impact and implications. Expert Rev Pharmacoecon Outcomes Res 10: $73-85$.

18. Hassali MA, Stewart K, Kong DC (2008) A national survey on knowledge and perceptions of senior medical students in Australia about generic medicines Med J Aust 188: 123-124.

19. DeVellis RF (1991) Scale Development. Theory and Applications. Applied Social Research Methods Series, Vol 26. Neybury Park: Sage.

20. Lawshe $\mathrm{CH}$ (1975) Aquantitative approch to content validity 1. Personne Psychology 28: 563-75.

21. Oppenheim AN (1998) Questionnaire design, interviewing and attitude measurement: Pinter Pub Ltd.

22. Hinton PR, Brownlow C (2004) SPSS explained, 2004. Routledge NY.

23. Hinton PR, Brownlow C, McMurray I (2004) Cozens. SPSS Explained.

24. Dawson B, Trapp RG (2004) Basic \& clinical biostatistics: McGraw-Hill.

25. Stokes ME, Davis CS, Koch GG (2006) Categorical data analysis: Using the SAS System: SAS institute.

26. Kuzon Jr WM, Urbanchek MG, McCabe S (1996) The seven deadly sins of statistical analysis. Ann Plast Surg 37: 265-272.

27. Millis SR (2003) Statistical practices: The seven deadly sins. Child Neuropsycho 9: 221-233.

28. Knapp TR (1990) Treating ordinal scales as interval scales: an attempt to resolve the controversy. Nurs Res 39: 121-123.

29. Jamieson S (2004) Likert scales: how to (ab) use them. Med Educ 38: 1217 1218.

30. Pell G (2005) Use and misuse of Likert scales. Med Educ 39: 970-971.

31. Federal Research Division (2006) Federal Research Division Country Profile: Iraq. Library of Congress.

32. USFAD FaDA (2002) Center for Drug Evaluation and Research. What are generic drugs?Available from: http://www.fda.gov/cder/ogd/index. htm\#Introduction. Accessed: April 16, 2002.

33. Godman B, Haycox A, Schwabe U, Joppi R, Garattini S (2008) Having you cake and eating it: Office of Fair Trading proposal for funding new drugs to benefit patients and innovative companies. Pharmacoeconomics 26: 91-98.

34. Pearson SA, Rolfe I, Smith T (2002) Factors influencing prescribing: an intern's perspective. Med Educ 36: 781-787. 